\title{
Emancipação ou embrutecimento e as interfaces entre corpo, cidades e tecnologias ${ }^{1}$
}

\section{Emancipation or brutalization and the interfaces between body, cities and Technologies}

Rogério Rodrigues

Resumo: 0 objetivo deste artigo é analisar as relações entre o corpo, cidades e tecnologias em interface com os processos formativos do sujeito. 0 ponto central seria evidenciar como as referidas interfaces podem constituir uma determinada representação de mundo e, principalmente, resultar no modo de vida dos sujeitos que podem se apresentar na ambivalência entre as práticas emancipatórias e o embrutecimento. Para tanto, parte-se da análise do uso técnico de corpo como processo de construção social que estabelece a dualidade entre emancipação ou embrutecimento que se pode evidenciar no interior das cidades no campo da teoria crítica. Para analisar os processos formativos do sujeito a metodologia utilizada encontra-se no âmbito da Filosofia da Educação, no sentido de compreender apropriação crítica do conceito de cidadania como resultado do projeto arquitetônico urbanístico em que somos, em parte, resultado do modo como vivemos nas cidades. Concluiuse que no processo formativo do sujeito encontra-se no paradoxo, por um lado, a construção da cidade pelo viés democrático como lugar para se fazer o espaço do comum na partilha do sensível. Por outro lado, o autoritarismo na segregação dos espaços aos sujeitos.

Palavras-chaves: Interdisciplinaridade. Educação. Cidades.

\begin{abstract}
The objective of this article is to analyze the relationships between the body, cities and technologies in interface with subject's formative processes. The central point would be to show how the referred interfaces can constitute a certain representation of the world and, mainly, to result in the way of life of the subjects who can present themselves in the ambivalence between emancipatory practices and stupidity.For such, we start from the analysis of the technical use of body as a process of social construction that establishes duality between emancipation or brutalization which is evident inside the cities in the critical theory field. To analyze the subject's formative processes,
\end{abstract}

\footnotetext{
${ }^{1}$ Agradecimento à Universidade Federal de Itajubá (UNIFEI) e aos alunos do segundo semestre de 2019 do curso "Corpo, Tecnologias e Cidades" do programa de mestrado em Desenvolvimento, Tecnologias e Sociedade da Universidade Federal de Itajubá (UNIFEI).

*Doutor e Mestre em Educação (UNICAMP) e Professor Titular da Universidade Federal de Itajubá - UNIFEI. e-mail: rrunifei@hotmail.com
} 
the methodology used is within the scope of the Philosophy of Education, in order to understand the critical appropriation of the citizenship concept as a result of the architectural project in which we are partly the result of the way we live in cities. It was concluded that in the subject's formative processes is found in the paradox, on one hand, the city construction by the democratic bias as a place to make up the common space in sharing the sensitive. On the other hand, authoritarianism in segregating spaces from subjects.

Keywords: Interdisciplinarity. Education. Cities.

Recebido em: 26/05/2020. Aceito em: 23/03/2021

\section{Introdução - o uso técnico do corpo como máquina: cultura corporal e produção de subjetividade}

Partimos do pressuposto de que, para se pensar na atualidade das cidades, deve-se analisar os processos de formativos como elementos constituintes do modo de ser dos sujeitos e, principalmente, na construção da representação do imaginário dos espaços urbanos, basicamente, em duas vertentes: emancipadora ou embrutecimento. Desse modo, compreendemos os processos de formativos como uma categoria chave para se analisar as interfaces entre corpo, cidades e tecnologias na construção ou desconstrução da cidadania.

A ampliação das cidades e a concentração de habitantes instauram outros determinantes nos processos formativos que interagem com diversos fatores e constituem o paradoxo que compreende o sujeito, por um lado, pelo viés do senso comum, no paradigma da determinação do vir a ser, e por outro lado, pelo viés da teoria crítica, na indeterminação do vir a ser. Portanto, na oposição do senso comum e da teoria crítica, coloca-se em questão, respectivamente, de um lado, a compreensão do sujeito como resultado de algo naturalizado, na qual adquirimos o conjunto de nossas práticas corporais como uma natureza própria do sujeito. Por outro lado, a compreensão crítica do sujeito como aquele que atua manifestando o sintoma no campo das formações do inconsciente, cuja inserção na cultura é algo muito tênue, pode se romper e constituir a barbárie (FREUD, 1990).

Nesse contexto, a nossa proposição teórica para se analisar os processos formativos encontra-se no paradoxo do campo da teoria crítica referente, principalmente, à compreensão das interfaces entre os espaços urbanos e a educação do corpo. Neste lugar do uso técnico do corpo, é importante destacar que fazemos uma recusa na distinção entre natureza e cultura, pois compreendemos a natureza da técnica de corpo adquirida pelo sujeito encontra-se no âmbito da cultura da sociedade em que este se encontra inserido (MAUSS, 1974).

Nessa perspectiva, pensar a interação entre os sujeitos e as cidades no contraditório entre natureza e cultura altera por completo a interpretação sobre o processo formativo como algo determinista e naturalizado. A nossa compreensão de sujeito é que este resulta da interação dialética em que se apresentam as diversas contradições, cujo resultado é inédito, em termos de sujeito no campo da cultura. Desse modo, ocorre o paradoxo no processo formativo nas interfaces entre corpo, cidades e tecnologias, que, de um lado, a cultura apresenta-se como elemento 
estruturante dessas relações, mas, por outro lado, ocorre um espaço para a indeterminação no vir a ser sujeito.

Nesse sentido, resta saber, no âmbito do uso do corpo, na interface com as metrópoles, o que se permite colocar em evidência é possibilidade da emancipação do sujeito, uma vez que nas relações com a cultura ocorre o processo civilizatório. Entretanto, pode-se também compreender que o embrutecimento ocorre como processo de precarização na inserção no campo da cultura, numa interpretação de que isso é algo próprio do estado de regressão do sujeito na manifestação da barbárie.

Compreendemos a polaridade entre a natureza e cultura, civilização e barbárie ou emancipação e embrutecimento como resultados diretos dos processos formativos, no sentido de que os sujeitos são produzidos ou reproduzidos numa determinada concepção de mundo e, portanto, não é nada natural o modo de ser do sujeito perante o mundo.

No momento em que se aborda essa questão dos sujeitos no processo formativo, nas interfaces entre corpo, cidade e tecnologias para além da naturalização, fica definida a responsabilidade dos gestores públicos em compreender que as cidades são como livros abertos, que definem uma determinada interpretação e, principalmente, uma representação de mundo aos sujeitos.

A possibilidade de ruptura para se compreender o sujeito para além do determinismo cultural que naturaliza o sujeito apresenta-se na destituição da hierarquia como perspectiva analítica para se compreender, numa relação de igualdade, que não existem povos não civilizados, mas apenas povos de civilizações diferentes (MAUSS, 1969, p. 229-30).

No conjunto dessa diferença ou igualdade é que se pode compreender toda a manifestação política dos diversos resultados dos processos formativos. Numa relação de igualdade no campo da formação do sujeito, permite-se o pleno diálogo na interface com os espaços urbanos em que somos constituídos e alterados no indeterminismo do nosso vir a ser (SARTRE, 1997).

Neste contexto, do não saber sobre os resultados dos processos de formativo na constituição dos sujeitos, é que se deve compreender toda a educação formal ou informal para além daquilo que está estabelecido nas diversas formas de atividades presentes na educação física como algo natural pautado em "aptidões naturais" (BISSERET, 1979), e que tem como base a compreensão da ciência reducionista no campo da tradição cartesiana do corpo máquina (DESCARTES, 1980).

No campo da tradição cartesiana, a educação do corpo encontra-se estruturada num aspecto determinista como resultado vetorial, em que o sujeito é atravessado por forças mecânicas, que no campo da cultura corporal se pautam numa ciência de resultado. Todo o movimento corporal humano é interpretado e plenamente comprendido como resultado de resultados de ações disciplinares que nele produzem a eficácia e a eficiência do uso das técnicas do corpo inserido no social, que se contrapõem a esse determinismo como uma interferência que deve ser controlada. Desse modo, no campo da educação física, o rendimento da técnica do corpo é algo que se encontra no paradoxo da dependência do biológico e do social que o impregna de cultura e, simultâneamente, na regulação adequada que se constitui no homem-máquina. Portanto, o corpo humano nada mais é que uma máquina enigmática, integrada por peças, como um autômato, que funciona numa engrenagem entre ossos e músculos (DESCARTES, 1980, p. 41). O seu rendimento está diretamente relacionado ao condicionamento físico que o torna ao desempenho motor das funções corporais em proximidade com os controles estabelecidos entre os adequados estímulos para o alcance de bons resultados.

A natureza desse homem-máquina constitui-se como uma representação de objeto e, portanto, os elementos da cultura passam ser a linha de corte entre aqueles que podem ou não obter 
bons resultados. Assim, constituiu-se numa interpretação hegemônica para explicar as aptidões para o desempenho físico como representação das lutas de classes sociais, que se expressam no campo da disputa ideológica (BISSERET, 1979).

Compreendemos que, no âmbito da educação física, tradicionalmente, ocorre uma ampliação da hegemonia da naturalização pautada numa concepção mecanicista do movimento corporal humano, uma vez que o campo da crítica não circula plenamente nesses territórios, como já identificou Bourdieu (1990), que declara que existem campos fechados e que

[...] grandes atletas negros, que nos Estados Unidos em geral são pagos por grandes universidades, como a Universidade de Stanford, vivem numa espécie de gueto dourado, pelo fato de as pessoas de direita não falarem de bom grado com os negros e as de esquerda não falarem de bom grado com os esportistas. Se refletirmos sobre isso, desenvolvendo-lhe o paradigma, talvez encontremos aqui o princípio das dificuldades particulares que a sociologia do esporte encontra: desdenhada pelos sociólogos, ela é desprezada pelos esportistas (BOURDIEU, 1990, p. 207).

Entretanto, essa condição dos guetos práticos e teóricos encontra-se também no paradoxo de não se explicar as diferenças do uso do corpo no campo da cultura, ao compreender que somente no músculo e na aptidão natural é que se pode constituir o modo apropriado de explicar o seu uso. Portanto, os estudiosos deveriam colocar toda a tradição cartesiana em dúvida, assim como próprio Descartes (1987) o fez com o seu método para se analisar a possibilidade do conhecimento e, assim, deveríamos desconfiar dessa concepção de uso do corpo que ainda se encontra impregnada nos dias atuais por toda uma representação de coisa, ou seja, não somos nada além de objetos manipuláveis que se ordena numa relação pautada na hierarquia daquele que manda e o outro que obedece e que

[...] não é qualquer um que pode em qualquer lugar e em qualquer ocasião dizer qualquer coisa a qualquer outro. $O$ discurso competente determina de antemão quem tem o direito de falar e quem deve ouvir, assim como predetermina os lugares e as circunstâncias em que é permitido falar e ouvir, e, finalmente, define previamente a forma e o conteúdo do que deve ser dito e precisa ser ouvido. [...] Em uma palavra, a ideologia da competência institui a divisão social entre os competentes, que sabem, e os incompetentes, que obedecem (CHAUI, 2016, p. 187).

Em nossa compreensão, a pergunta central para se analisar os processos formativos para além do senso comum, que naturaliza o sujeito nas interfaces com os espaços urbanos seria: na atualidade, torna-se possível romper com o conceito do corpo enquanto objeto mecânico, como máquina que se encontra na hegemonia do reducionismo biológico?

A resposta a esse questionamento encontra-se, em parte, na compreensão de que essas formas disciplinares de corpo tornam-se necessárias para o adestramento e disciplinamento de um determinado tipo de corpo produtivo, em termos de desempenho da força de trabalho que se encontra numa concepção de mundo, ciência e sociedade, que justifica as diferenças, naturalizando o conjunto das relações humanas.

Neste contexto de desnaturalizar o campo das relações humanas, a educação física torna-se uma atividade necessária para a vida em cidades emancipadoras, já que cada vez mais se exige do corpo, resultados e desempenhos, na necessidade de: 
Adaptar, portanto, esse mesmo cidadão aos sistemas, rotinas e automatismos desse grande e complexo aparato metropolitano passa também a ser um problema das autoridades dirigentes, devendo ser tecnicamente resolvido segundo competências superiores. Para se tomar um único exemplo, atravessar uma avenida expressa, especialmente em horário de rush, é um ato ousado que demanda uma sofisticada combinação de instintos, reflexos, coordenação motora e disciplina de atos concatenados. Como essa combinação complexa nós é incorporada desde cedo na vida, é muito difícil por isso atentar para o quão exigente esse pequeno ritual cotidiano pode ser (SEVCENK, 1994, p. 34).

Temos uma interface entre o uso corpo e o social, que coloca em questão toda tradição de pensamento que o restringem na compreensão de que seu uso decorre apenas de ações musculares não relacionadas no campo da cultura. Entretanto, aqui também se apresenta outra coisa, a se destacar de que, no uso do corpo nos processos formativos, institui-se no sujeito uma determinada representação de mundo, em que este se encontra inserido no social como sujeito, mais propriamente, aquele que é dividido na produção de sintomas. Essa representação de sujeito dividido torna-se representado numa oposição a concepção liberal de indivíduo como aquele não dividido e que, apropriado da razão esclarecida, pode atuar na igualdade, liberdade e fraternidade.

Nos processos de formativos, esses elementos do liberalismo na representação de individuo como aquele não dividido se apresentam num paradoxo, pois, apesar de todos os esforços, a concentração de habitantes e a ampliação das cidades produzem sujeitos incontroláveis. Apesar de todos os esforços pautados numa fisicalidade das mecânicas dos corpos e seu reducionismo biológico na transmissão da técnica do corpo, o que se evidencia nos processos de formativos é reprodução da desigualdade, o aprisionamento e a violência. Nesses lugares da produção de subjetividades, para aquém da razão constituída da igualdade, liberdade e fraternidade, dever-se-ia compreender que

O planeta Terra vive um período de intensas transformações técnico-científicas, em contrapartida das quais engendram-se fenômenos de desequilíbrios ecológicos que, se não forem remediados, no limite, ameaçam a vida em sua superfície. Paralelamente a tais perturbações, os modos de vida humanos individuais e coletivos evoluem no sentido de uma progressiva deterioração. As redes de parentesco tendem a se reduzir ao mínimo, a vida doméstica vem sendo gangrenada pelo consumo da mídia, a vida conjugal e familiar se encontra frequentemente "ossificada" por uma espécie de padronização dos comportamentos, as relações de vizinhança estão geralmente reduzidas a sua mais pobre expressão. (GUATTARI, 2009, p. 7-8).

Resolver essa questão é lidar diretamente com os processos formativos como um problema no campo da política, em que a educação do corpo deveria ser compreendida para além do reducionismo biológico. Isso significa olhar para o corpo em outras interpretações, para além de ser objeto manipulável.

O contra ponto para compreender o sujeito como objeto seria a política do corpo e a luta por hegemonia, que se podem transparecer nas interfaces entre corpo e as cidades, e se materializam em determinadas formas de tecnologias materiais e não materiais que produzem, respectivamente, formas objetivas no campo da cultura corporal e nas diversas concepções de mundo presentes nas subjetividades, e que também se expressam nas práticas de vida no interior das grandes cidades. 
Nesse sentido, partimos do pressuposto de que os processos formativos e as interfaces entre corpo, cidades e tecnologias constituem no, âmbito do movimento corporal humano, um lugar privilegiado de observação para se compreender como se realiza a produção ou reprodução da subjetividade na interface do sujeito no campo da cultura, mais propriamente, no campo da cultura corporal, que estaria presente em diversos detalhes estabelecidos no interior das cidades. Desse modo, as formas constituintes que se fazem presentes nas tramas e fazeres cotidianos são matérias-primas de consumo para a reprodução da subjetividade, tendo como base as relações que se estabelecem entre o uso técnico do corpo (MAUSS, 1974) e a sociedade, mais propriamente, as cidades como resultado do processo de metropolização como perspectiva política de sujeito.

Para se compreender essas mediações entre a cultura corporal e as metrópoles, o nosso ponto inicial seria analisar a objetividade que se apresenta nas coisas do corpo e os modos de cidade que são representadas pelos sujeitos como forma de expressão das coisas, mediadas pelas formas de tecnologias, que estabelecem as determinações no modo como os nossos corpos são usados ao circularmos pelas cidades.

\section{A questão do método: o corpo e as relações com a arquitetura pautada no paradigma dos muros}

Em nosso processo de investigação sobre esse tema, corpo, cidades e tecnologias se apresentam como algo que gira em torno das formas de reprodução de subjetividade, que se encontram presentes em detalhes que escapam de uma visão ampla das metrópoles e, portanto, para entendermos essa dimensão ampla de ação sobre o uso do corpo, faremos primeiramente o inverso, ou seja, compreender como, no lugar pequeno das metrópoles, somos afetados por essas determinações no campo da cultura corporal. Para tanto, seria importante analisar o uso técnico do corpo pelo viés da cultura que se impõe no sujeito, basicamente, por dois caminhos, que seria compreender aquilo que os sujeitos fazem em si mesmo e com os seus próprios corpos, ou naquilo que eles dizem sobre si mesmo e os seus feitos em termos de práticas corporais na vida em cidade. Em ambos os casos, entre o fazer e o dizer, o que há são representações simbólicas sobre o conjunto das práticas corporais e, muitas vezes, isso significa retornar a algo e compreender que o que se busca dizer geralmente não se encaixa naquilo que é dito, pois "não adianta dizer o que se vê; o que se vê não habita jamais o que se diz” (DELEUZE \& GUATTARI, 2014, p. 107).

Neste caso, no uso do corpo nos pequenos lugares, naquilo que faz e que se diz, e até mesmo no que se vê, no campo das representações, as tecnologias passam a se constituir como elemento mediador entre os elementos objetivos e as expressões de subjetividade, pois aquilo que eu produzo e suas representações encontram-se mediadas por essas maneiras de fazer as coisas nos grandes lugares das cidades que se constituem as metrópoles.

Desse modo, as tecnologias que determinam o uso do corpo podem ser compreendidas como fabrica produtoras de cultura ou numa resistência na interdição dos próprios elementos da cultura. Conforme já anunciado, anteriormente, na tradição cartesiana de corpo máquina, esse campo e subjetividades se impõem na hegemonia e se baseia em práticas conscientes e inconscientes, constituídas nos processos formativos e caberia aprofundarmos a questão de saber que

Particularmente, o profissional da área da Educação Física desenvolve a tarefa de "agente cultural" no âmbito da mais decisiva intimidade, pois atua no sentido de implantar no próprio movimento humano os ditames da cultura. Assim, a denominação do professor de Educação Física como "educador do movimento" assume uma certa veracidade e, em inúmeros casos, uma certa 
tragicidade! Afinal, cabe ao "educador do movimento" a tarefa de engravidar o movimento humano de cultura, mais precisamente, de uma determinada cultura (GHIRALDELLI, 1988, p. 53).

A partir desse paradigma, é que temos como objetivo compreender como as cidades nos processos de metropolização também se constituem em espaços de máquinas em "engravidar o movimento humano de cultura" como elemento estruturante, em que vias e praças públicas desenham uma determinada representação de corpo. Para tanto, o nosso foco de análise seria compreender a presença de elementos inconscientes, não anunciados pela razão cartesiana e que também se impõem como transmissão dos elementos da cultura pelo viés das tecnologias que inserem no sujeito o mundo que o cerca, em que o saber fazer ou a representação dos modos de fazer as coisas com o corpo podem se apresentar como um elemento contraditório, já que em nossa modernidade:

O conceito de cultura é profundamente reacionário. É uma maneira de separar atividades semióticas (atividades de orientação no mundo social e cósmico) em esferas, às quais os homens são remetidos. Isoladas, tais atividades são padronizadas, instituídas potencial ou realmente capitalizadas para o modo de semiotização dominante - ou seja, elas são cortadas de suas realidades políticas (GUATTARI \& ROLNIK, 2005, 21).

Compreendemos que, no campo da cultura, o uso do corpo e a representação desse uso se constituem de modo "profundamente reacionário", uma vez que nos recusamos a ser diferentes do que somos e daquilo que pensamos sobre o modo como usamos as nossas técnicas de corpo, pois "cada sociedade tem hábitos que lhe são próprios" (MAUSS, 1974, p. 213). De modo mais específico, ficamos presos, teimosamente, em nós mesmos, amarrados pelas técnicas de corpo que definem o nosso modo de ser sujeito, o que Marcel Mauss (1974) compreende como resultado de "[...] processos que aplicamos aos animais foram aplicados pelos homens voluntariamente a si mesmos e a seus filhos" (MAUSS, 1974, p. 220). Essa educação de técnica de corpo se constitui num campo próprio de investigação da subjetividade uma vez que

[...] a criança como o adulto, imita atos que obtiveram êxito e que ela viu serem bem sucedidos em pessoas em quem confia e que têm autoridade sobre ela. $\mathrm{O}$ ato impõe-se de fora, do alto, ainda que seja um ato exclusivamente biológico e concernente ao corpo (MAUSS, 1974, p. 215).

No campo dessa educação do corpo, avaliamos que o modo apropriado de investigar as produções de subjetividade seria remetermos a situações corriqueiras do nosso cotidiano nos pequenos espaços no interior das cidades, e isso me remete a uma conversa que tive em certo dia, no final do treino do Kendo (Ken= espada e Do = caminho) que consiste numa luta com espada de bambu, na qual uma colega disse algo sobre a reprodução de subjetividades no campo das práticas corporais ou culturais, com as seguintes palavras: "O Kendo é uma máquina de fazer o sujeito ser japonês".

A partir dessa ideia é que se pode compreender que toda cultura funciona como uma máquina de subjetividade, que encontra no corpo os mecanismos para realizar essa ação que nos molda como sujeitos.

No caso específico, a tradição da cultura japonesa também se encontra presente no uso técnico do corpo na prática do Kendo restrito a área de luta (dojo), em que se possui toda uma 
etiqueta numa disciplina para o uso do corpo no espaço e no tempo. Todo o treino do Kendo se constitui num dispositivo de luta com a espada, no qual se busca os ajustes de aproximação e distância calculada numa representação que destitui o cartesianismo físico e se compreende o oponente, numa metafísica para realização do golpe como parte necessária de si mesmo para o uso técnico do corpo.

Desse modo, a afirmação dessa colega muito me chamou a atenção e me fez pensar a prática do Kendo, que, com as devidas proporções em compreender o uso técnico do corpo como máquina social que nos transforma e, principalmente, o espaço da luta como algo similar aos espaços ampliados numa cidade, que também se apresenta como máquina, em que todas as representações e mobilidade dos sujeitos encontram-se pré-construídas em algo que se altera a todo o momento e que determina as relações entre os sujeitos, contudo, não controlamos os seus resultados.

Tendo como base o exposto, partimos do pressuposto de que estudar as relações entre corpo e cidades mediadas pelas tecnologias seria compreender como os diversos dispositivos de técnicas se relacionam com a dinâmica dos espaços das cidades que produzem nos sujeitos determinadas formas de interpretação de si mesmo e dos outros. Portanto, compreendemos que o uso das tecnologias define uma determinada perspectiva de produção de modos de representação de sujeitos, ou mais propriamente, como nos tornamos aquilo que somos ou (NIETZSCHE, 1995).

Entretanto, torna-se necessário que possamos apresentar, no interior dessa outra concepção de educação do corpo, em interface com as cidades, a preocupação de como se torna possível realizar as possíveis formas de compartilhamento do saber comum que se constitui no processo civilizatório no campo da cultura em que

Denomino partilha do sensível o sistema de evidências sensíveis que revela, ao mesmo tempo, a existência de um comum e dos recortes que nele definem lugares e partes respectivas. Uma partilha do sensível fixa, portanto, ao mesmo tempo, um comum partilhado e partes exclusivas. Essa repartição das partes e dos lugares se funda numa partilha de espaços, tempos e tipos de atividades que determina propriamente a maneira como um comum se presta à participação e como uns e outros tomam parte nessa partilha (RANCIÈRE, 2009, p. 15).

Desse modo, os movimentos sociais apontam para algo oportuno na questão do corpo, quando coloca em questão a possibilidade de circular pelas cidades, uma vez que ter acesso ao ir e vir pela cidade constitui num direito a diversos bens sociais uma vez que "A mobilidade urbana é uma questão central para as sociedades contemporâneas e nelas desempenha diferentes funções" (GREGORI, 2018).

Nesse sentido, o referido ensaio se propõe a abordar, basicamente, as seguintes questões do corpo no campo das produções das subjetividades e cidades: o corpo e as relações com a arquitetura; os processos formativos e as representações de corpo na cidade; e, por último, as novas configurações de como os sujeitos ocupam as cidades e as diversas alterações na subjetividade. O reconhecimento dessa interface requer dos gestores dos espaços públicos, nas grandes cidades, a responsabilidade de fazer circular, nos diversos lugares, as variadas possibilidades de representação de uso de corpo e, portanto, o reconhecimento de que as tecnologias não são neutras e "engravidam" o sujeito numa determinada representação de mundo como resultado dos processos de metropolização.

Para se compreender as interfaces entre os processos de metropolização e as interfaces entre as técnicas do corpo e as cidades mediadas pelas tecnologias, optamos em dividir a nossa 
análise sobre o tema em questão, basicamente, em dois aspectos: em primeiro lugar, vamos analisar o uso do corpo como lugar em que se constituem nas expressões de tecnologias; e em segundo lugar, buscaremos compreender os diversos espaços das cidades também como tecnologias para o uso necessário da existência humana, apresentando-se de modo diversificado nas moradias e vias de acessos. Portanto, de um lado, constituem o modo individual, particular no estilo de vida e, por outro lado, representam a cultura na expressão da forma coletiva, na partilha do mesmo comum a todos - o espaço público.

Nesse caso, tanto o uso do corpo e o uso do espaço comum às ruas, praças públicas e, principalmente, os demarcados pelos muros, como espaços particulares, seriam outros lugares que expressam uma determinada concepção de mundo no campo da cultura.

o que seria importante destacar é que, muitas vezes, o que seria o lugar comum a todos, encontra-se distante das necessidades dos comuns e pode representar concepções de cidade e corpo que se constituem em formas contraditórias. O que prevalece atualmente é uma concepção ampliada do particular e uma redução do que é comum a todos, pois vivemos uma sociedade pautada no "narcisismo da pequena diferença" (FREUD, 1990, p. 119), mais propriamente, constituída num conjunto de interdições para a circulação das diferenças de corpos pelas cidades. No caso específico das cidades, vivemos numa era de perda de identidades, em que o singular prevalece como comum a todos, e as cidades se tornam iguais, num mesmo paradigma, com os apagamentos das marcas da cultura local em que:

Os turistas, por exemplo, fazem viagens quase imóveis, sendo depositados nos mesmos tipos de cabine de avião, de pullman, de quartos de hotel e vendo desfilar diante de seus olhos paisagens que já encontraram cem vezes em suas telas de televisão, ou em prospectos turísticos (GUATTARI, 2000, p. 169).

Analisar essas condições do apagamento das marcas da cultura presentes nos corpos e nas cidades significa compreender os poucos detalhes que restam presentes no uso do corpo e nas formas de habitações, as ruas e praças públicas, como formas de tecnologias destituídas de sentido e lugar que educam os sentidos dos sujeitos. Partimos da referência teórica que, entre a carne e a pedra (SENNETT, 1997), tornamo-nos sujeitos em determinadas sensibilidades constituídas para a vida em cidade e, portanto, constitui-se a educação do corpo como lugar de reprodução de subjetividade nas interfaces entre as cidades e as tecnologias. Assim, as cidades funcionam como elementos que se constroem no nosso modo sensorial perceptivo, que se pode compreender como processo de:

Reinventar o urbano, portanto, é reinventarmos a nós mesmos, reeducando nosso olhar em meio à torrente de estímulos, reposicionamento nosso corpo em meio a uma permanente inconstância de referências espaço-temporais [...]. (DANTAS, 2018, p. 112).

Entretanto, discordamos de Dantas (2018), ao considerar que esse processo de "inconstância de referências espaços-temporais" seria algo que faria o trabalho de "[...] recondicionando nosso cérebro em meio a um oceano não-processável de informações” (DANTAS, 2018, p. 112). Partimos do pressuposto de que uma coisa é compreender o que nos torna sujeito e representação de corpo como algo relacionado ao modo de vida em cidade. Outra coisa é colocar em discussão que a nossa adaptação ao meio de vida em cidade é da ordem do corpo biológico. Essa condição estabelece uma cisão entre corpo e mente ou, mais propriamente, corpo e cidade, em que somos neuralmente estimulados a sermos um determinado tipo de corpo em meio à vida em cidade. 
Diria que a cidade recondiciona o corpo como um todo, uma vez que dificilmente se podem representar as cidades e as formas de tecnologias como algo não imbricado aos nossos sentidos, em que a própria ação do tempo modifica o que somos e os espaços que ocupamos nas cidades.

Nessa dinâmica que se apresenta nas cidades, o nosso objetivo central seria em compreender como as relações entre a cultura corporal e cidades se constituem em elementos afetados pelas tecnologias no interior dos processos de metropolização, ao ponto de transformarem ou padronizarem as nossas representações de corpo e constituírem em reprodução de subjetividades, que ocorrem em um declínio da sensibilidade da compreensão do "sujeito para si" no vir a ser, que rompe com a fixação em determinadas verdades sobre o que o sujeito é, no sentido de constituí-lo como um "ser em si" (SARTRE, 1997).

Compreendemos que o tema cidade e corpo se encontram inserido nas dinâmicas estabelecidas nas contradições da sociedade moderna, na perspectiva multidisciplinar, na qual a representação de corpo e cidade estabelece relações entre o sujeito e o espaço como forma de produção de subjetividade, em que se:

[...] captam a energia do desejo dos trabalhadores, esforçam-se para dividi-los, particularizá-los e molecularizá-los. Infiltram-se em suas fileiras, suas famílias, seus casais, sua infância; instalam-se no coração de sua subjetividade e de sua visão de mundo (GUATTARI, 1981, 186).

Nesse sentido, o olhar sobre as coisas da cidade requer uma atenção especial em que cada elemento constituído se desdobra como forma de reprodução da objetividade e subjetividade e, nesse aspecto, por exemplo, analisar os muros das cidades, como se tornam elementos necessários, no sentido de compreender como os corpos podem ou não circular livremente pelos espaços e, principalmente, como isso é representado no imaginário social. Portanto, o nosso recorte de análise se trata pode ser algo relacionado diretamente como os muros e como isso se apresenta em formas de tecnologias que expressam a noção de propriedade comum e privada e, principalmente, como uma forma de apropriação política de sujeito na vida em cidade, e que promove como uma determinada educação de corpo e subjetividade.

Como exercício de pesquisa sobre esse ponto, poderíamos realizar um determinado recorte geográfico da cidade e, a partir de indicadores econômicos, observar os tipos de muros que se apresentam como tecnologias naquele lugar e, principalmente, como os mesmos são representados pelos sujeitos. Diante dessa situação, não se torna possível discutir a emancipação, cidadania, liberdade, consciência crítica, enfim qualquer elemento no campo da política do sujeito, se não colocarmos primeiramente em discussão a questão da vida do sujeito na polis. Portanto, a questão do muro como uma barreira física que impede a livre circulação ou os outros tipos de muros, que se estabelecem numa imaterialidade, constituindo uma dificuldade de acesso em linhas de transporte público, tempo disponível de lazer, recursos financeiros para o exercício do passeio, enfim, são tantos outros fatores que impedem o acesso, que podemos produzir um método de investigação para a questão do corpo e as relações com a arquitetura pautada no paradigma dos muros.

Com essas referências acerca do tema corpo e cidade, a nossa questão metodológica central seria analisar as interfaces no campo das tecnologias, ao compreender que esse fenômeno (corpo e cidades) encontra-se mediado por instrumentos que se instalam como elementos presentes no campo da política, no sentido de expressão ou repressão daquele sujeito que vive na cidade. A nossa referência de estudo ao tema da arquitetura do muro está fundamenta no campo da Filosofia 
da Educação, no sentido de compreender esses dispositivos de técnicas de corpo (MAUSS, 1974) ou os arquitetônicos, como parte do processo formativo disciplinar em que o sujeito torna-se conduzido para não ir e não vir, na condição emancipatória, em que o ir seja para o pleno consumo de coisas numa sociedade onde a maioria dos casos tem como paradigma de vida coletiva algo que orbita em torno do shopping Center.

Cabe destacar que essa invenção da arquitetura moderna como espaço do consumo trabalha com a questão do tempo de modo muito significativo, pois pode-se verificar que nos shopping Center, em sua grande maioria, não há janelas. Ao entrarmos nesses templos do consumo perdemos o contanto com o tempo da natureza que se produz nas oposições entre a luz do sol e o escurecer. No interior do shopping Center, vivemos um tempo artificial, no qual não há noite, ao contrário, sempre temos luz para caminharmos em direção às mercadorias que nos esperam nas prateleiras.

A modernidade impôs a luz do conhecimento para a "caverna platônica" (PLATÃO, 1996), entretanto, continuamos a não conhecer as coisas para além do fetiche, e ainda nos distraímos em encontrar a felicidade nas compras com o cartão de crédito, ou em condomínios fechados, que precariamente reproduzem a vida em sociedade.

Desse modo, ocorre um fenômeno interessante de alteração na visibilidade e circulação dos corpos: nas sociedades medievais, o comércio era feito no lado de fora do castelo, este era o centro político, e os burgos se constituíam no entorno das fortalezas dos muros, que se apresentam um universo praticamente estático. Passamos para a modernidade, em que a governabilidade se torna difusa e se apresenta numa outra tática do poder, numa outra dinâmica, em que nada se torna permanente, contudo ainda prevalecem os muros, num outro paradigma se espalharam e especializaram para todo o espaço urbano.

Diria que o centro político na modernidade se torna difuso, espalhados pelas cidades, em diversos muros e lugares de shopping Center. Desse modo, torna-se evidente que a alteração política dos espaços coletivos e individuais do mundo feudal para a organização do capitalismo moderno produz acentuadas alterações no uso do corpo e no modo de vida nas cidades em suas específicas produções tecnológicas, em que a máquina do controle encontra-se constituída no panóptico (FOUCAULT, 1991).

\section{Resultados: os processos formativos e as representações de corpo na cidade}

Pensar no resultado deste estudo, nas interfaces entre os processos formativos, corpo e cidade, mediados pelas tecnologias, implica em querer responder como a sociedade moderna representa para si a vida em coletividade. A partir dessa indagação temos como resultado deste ensaio a ideia de que a cidade é o lugar onde se imprime no corpo o modo de vida que se realiza ou se interdita elementos da cultura no sujeito. Para tanto, torna-se possível compreender que, em determinadas condições objetivas, produzem-se uso e representações de corpo na cidade como lugar que educa a técnica de corpo (MAUSS, 1974) e produz subjetividade. Partimos do pressuposto de que as cidades se constituem em espaços que

A cidade é um produto da história e a história não é um produto do acaso. A história é o produto das escolhas que, conscientemente ou não, buscam impor a vontade de alguns sobre o desejo da maioria. A cidade não é um produto em construção, mas sim um processo em condução, orientado, compelido, estigmatizado por uma sequência de escolhas cumulativas. E a escolha nada mais é do que a diferença entre o que pode ser (possibilidade) e o que deverá 
ser (probabilidade), na busca de uma relação de ação e reação (causalidade) (DANTAS, 2018, p. 107).

O ponto central para se compreender esse processo formativo no sujeito seria pensar que, em relação ao corpo, a cidade que seria o ponto fixo, mas com a característica de que esse ponto fixo também possui toda uma dinâmica que se altera com o passar dos anos. Nessa relação entre o corpo e cidade, numa determinada perspectiva do sujeito com seu corpo, seria aquele que passa e olha e sente toda uma dinâmica que se estabelece no paradigma do ponto de observação em movimento e que se produz uma condição da visão em ver e sentir, em que

Por muito tempo, a humanidade conheceu apenas a imagem fixa (escultura, pintura, fotografia), que é também uma imagem-objeto que determina suas condições de percepção. Instalada sobre um suporte imóvel, a imagem exigia que o corpo que contempla se deslocasse, para melhor ver ou ver de outro modo. A imagem é o ponto fixo, o corpo, o observador móvel (WUNENBURGER, 2005, p.33).

Na modernidade, essa condição de contemplação entre o corpo e cidade tornar-se completamente alterada, uma vez que se instaura outro modo de olhar na perspectiva da era da televisão, em que a representação estabelece outra condição

Com a chegada da imagem móvel, o cinema primeiramente, a televisão em seguida, a imagem de síntese enfim, se produz uma verdadeira revolução copernicana: não é mais o homem que se move em torno ou diante da imagem, mas é a imagem que integra o movimento, a mudança para um observador fixo, fixado (WUNENBURGER, 2005, p.33).

Desse modo, analisar a questão dos processos metropolização e as representações de corpo na cidade, sob o olhar do sujeito moderno, requer compreender como o nosso modo de sentir e pensar que se encontram hegemonicamente constituídos num modo de perda da sensibilidade para o entorno, mais propriamente, as imagens da cidade são representações distorcidas pelos recortes estabelecidos a que nos acostumamos através das imagens da televisão.

Portanto, a análise empírica do referido fato dessa interface entre corpo e cidade consiste em discutir como os espaços das cidades se encontram organizados em dois espaços distintos, que podem nos apresentar o tema em questão. Para tanto, vou me referir a dois espaços que requerem determinados recortes de estilo de vida em sociedade: o município da Praia Grande e o município de Ubatuba. O que esses dois lugares possuem em comum é que se encontram localizados a beira-mar, mas o que eles possuem de diferente é como são organizados seus espaços, em decorrência de seus frequentadores que possuem olhares e sentimentos distintos em relação às interfaces entre corpo, cidade e tecnologias.

$\mathrm{Na}$ Praia Grande, os lugares coletivos e privados possuem um adensamento de pessoas que se apertam em conjuntos de "quitinete" e se alimentam na areia perto do mar, em torno de carrinhos de comidas com alto teor calórico. O referido município possui um adensamento de pessoal na orla marítima que é algo, muitas vezes, fora do comum e, segundo os dados do IBGE, possui uma população estimada de 330.845 (IBGE, 2020). No entanto, em algumas ocasiões, em decorrência dos feriados, "Na alta temporada, a população flutuante de Praia Grande aumenta até quatro vezes, ultrapassando, em determinados momentos, como Natal, Ano Novo e Carnaval, a marca de mais de 1 milhão de pessoas" (AGEM, 2020) que se aglomeram na faixa beira-mar. 
Completamente ao contrário dessa situação, em grande parte das praias de Ubatuba, os lugares de aglomeração de pessoas fazem parte do estilo de vida mais reservado na ocupação do espaço público. Portanto, a população local estimada em 91.824 habitantes (IBGE, 2020), em época de feriados e alta temporada, amplia-se com a população flutuante. Entretanto, a concentração de pessoas se organiza no entorno de acomodações das casas que são amplas e possuem apelativos ecológicos pautados em arquiteturas que recorrem à sustentabilidade. A grande diferença apresentada entre os sujeitos desses dois espaços está relacionada ao modo como habitam e ocupam os espaços públicos e privados.

No caso da alimentação, não se encontram carrinhos de vendas de alimentos nas praias, e os restaurantes têm cardápios sofisticados cuja ênfase é os alimentos saudáveis. Pode-se concluir que, entre esses dois espaços, o que se caracteriza é uma distinção de classe social e estilo de vida e, em nossa perspectiva de análise, a compreensão de "reinventar o urbano, portanto, é reinventar a nós mesmos” (DANTAS, 2018, p. 112) trata-se também de uma condição política do sujeito na vida em sociedade.

Entretanto, o que seria nessa condição de frequentar a praia, a presença de toda questão política de vida do sujeito? Partimos do pressuposto de que se analisar a vida em cidade seria identificar como a mesma se apresenta como expressão de tecnologias, em que os corpos apropriados ou desapropriados das tecnologias reconstroem seus estilos de vida numa sociedade pelo viés democrático, em que se exercita a partilha do sensível (RANCIÈRE, 2009), ou em sociedade autoritária, em que reproduzem os diversos espaços de guetos de exclusão. Tudo parece indicar que a oposição entre Praia Grande e Ubatuba é algo que está diretamente relacionado ao acesso a bens comuns ou à desapropriação desses elementos que se encontram no campo da cultura e que se expressam também no campo da cultura corporal.

\section{Considerações finais: os processos formativos e as novas configurações dos sujeitos ocuparem as cidades}

Podemos iniciar as nossas considerações finais com o seguinte questionamento: como os processos formativos instituem novas configurações de os sujeitos ocuparem as cidades e produzem alterações nas subjetividades nas distinções entre emancipação ou embrutecimento?

Temos como elemento conclusivo que aspectos do modelo econômico que gira em torno do capitalismo determina, em grande parte, as condições objetivas e subjetivas para os elementos que configuram o modo de existência dos sujeitos. Em termos objetivos, a condição financeira do sujeito estabelece uma linha de corte no seu modo de vida e, em termos subjetivos, é o modo como compreende a si mesmo para viver a sua própria condição de sujeito.

Compreendemos que o ponto central que ocorre nas alterações das cidades são as novas configurações no modo como os sujeitos ocupam os espaços e, principalmente, como eles são representados no campo discursivo como narrativas de existência dos sujeitos. Esses modos de representar as cidades podem ser, também, um modo de o sujeito representar a si mesmo como aquele que vive no espaço comum. $O$ verdadeiro paradoxo é que, cada vez mais, o espaço comum se representa como lugar pouco comum, pois a nossa contemporaneidade apresenta, como modelo ideal de vida, a privatização dos espaços como lógica de individualizar e encontrar a saída para os problemas do convívio social. Em última instância, o que se busca evitar é a presença do outro que constitui o mal-estar quando apresenta outras demandas para a existência (FREUD, 1990). 
Nesse contexto, o principal foco de mudança seria as alterações que ocorrem nos espaços das cidades, cujos espaços coletivos, em determinadas circunstâncias, vão se tornando espaços individuais, pois passa a ser comum que as ruas sejam privatizadas na formação de condomínios; as praças públicas sejam cercadas com grades; em espaços públicos, sejam colocadas catracas de restrição de acesso; enfim, torna-se comum a privatização dos espaços comuns das cidades. $O$ resultado dessa tendência é que todos podem olhar para a cidade e se identificar com um ponto de referência em que a vida individual se torna o paradigma de existência do sujeito na cidade. Nessa condição de transformação de individualização na vida do sujeito, ocorre o processo de identificação, os sujeitos podem constituir suas narrativas de vida numa determinada filiação à tese de que o sucesso resulta da competência individual (CHAUI, 2016), destituindo, por completo, a possibilidade da vida coletiva e enaltecendo a fixação em determinadas verdades de que o sujeito "é" a plenitude em ser indivíduo.

Compreender, criticamente, a interface entre o sujeito e a cidade seria possibilidade de trabalhar como um anteparo de pano de fundo, em que essas narrativas de existências ocorrem no sentido de constituí-lo como um "ser em si", que não é fixo em nenhuma verdade e está sempre em constante alteração, evitando o desamparo em "não ser" (SARTRE, 1997) num vazio que o impeça de compreender sua territorialidade que, aliás, se encontra no paradoxo em que:

O ser humano contemporâneo é fundamentalmente desterritorializado. Com isso quero dizer que seus territórios etológicos originários - corpo, clã, aldeia, culto, corporação... - não estão mais dispostos em um ponto preciso da terra, mas se incrustam, no essencial, em universos incorporais. (GUATTARI, 2000, p. 169).

Nesse universo de apagamento das referências dos territórios, são outras marcas que emergem com a força de produzir um discurso da identificação, mais propriamente, as mercadorias se estabelecem como ponto de fuga para uma existência que não mais sabemos o que somos como sujeito. Passamos rapidamente numa condição de ser humano para ter humano, em que a marca de consumo inscreve em cada um de nós um determinado estilo de vida, sentimento e modo de olhar para o mundo que nos cerca.

Nesse universo desterritorializado, em que as mercadorias estabelecem o paradigma da existência, as alterações nas cidades se constituem no dispositivo da inversão das circunstâncias, em que todos podem olhar e se identificar com um ponto de referência presente na cidade, ou cada um pode olhar para todos - a sociedade do panóptico (FOUCAULT, 1991) - em que se indica uma profunda alteração na condição subjetiva em que:

Somos bem menos gregos que pensamos. Não estamos nem nas arquibancadas nem no palco, mas na máquina panóptica, investidos por seus efeitos de poder que nós mesmos renovamos, pois somos suas engrenagens (FOUCAULT, 1991, 190).

No conjunto dessas engrenagens que se constituem como dispositivos de controle, o sujeito, na interface entre o corpo com o espaço da cidade, não se encontra nem de um lado (torre) nem de outro (arquibancada), e sim nas mediações que o fazem pensar e agir como torre ou pensar e agir como arquibancada. Nesta desconfiguração do território, é que deveríamos responder ao nosso questionamento primordial, se nessas condições existem as possibilidades de cidades de viés democráticos na circulação dos sujeitos (emancipação), ou a tendência é a permanência de constituírem em espaços de segregação dos sujeitos - entre muros (embrutecimento). 
Desse modo, podemos, por um lado, analisar que a construção da cidade de viés democrático seria compreender como o espaço de todos pode se constituir como lugar para se fazer o espaço do comum na partilha do sensível. Por outro lado, o autoritarismo seria o inverso, o lugar das cidades se organiza para restringem a grande parte da população, o acesso ao comum na segregação dos espaços aos sujeitos, e isso que nos faz retomar o ponto primordial de análise, a questão dos processos formativos e a educação do corpo como lugar de reprodução de objetividade e subjetividade nas interfaces entre as cidades e as tecnologias. Podemos concluir que ocorrem, nas cidades modernas, a hegemonia em que se ampliam as tecnologias dos muros que produzem verdadeiras prisões.

A distinção dessas prisões urbanas que se inserem nos espaços das cidades e as outras prisões, que são construções arquitetônicas específicas para encarceramento do sujeito, cada vez mais diminuem suas distinções. A única distinção possível que posso destacar é que, nas prisões do encarceramento, exageram-se nas janelas. Isso seria uma modalidade de impor a punição ao prisioneiro, pois o fato de fazê-lo sentir o tempo, naturalmente, transcorrendo a cada segundo é um castigo: nas prisões o tempo não passa. Já nos shopping Centers, que se constituem em prisões sem janelas, o tempo passa sem percebemos que seria apenas mais uma coisa que nos faz perder a sensibilidade de nossos corpos nas interfaces com as cidades e suas produções tecnológicas. A teoria crítica aponta que esse lugar de perda de sensibilidade como elemento de regressão do sujeito no campo da cultura (ADORNO, 1995), e aqui retorna como ponto fundamental a importância de compreender os processos formativos como elemento no campo da política da educação dos corpos, que pode estabelecer uma linha demarcatória entre a emancipação ou o embrutecimento no interior das cidades como lugar que se pode realizar o conceito de cidadania no conjunto das praticas dos sujeitos.

\section{Referências}

ADORNO, T. W. Educação após Auschwitz. In: ADORNO, T. W. Educação e Emancipação. Trad. Wolfgang Leo Maar. Rio de Janeiro: Paz e Terra, 1995.

AGEM. Agencia Metropolitana da Baixada Santista. Disponível em: < encurtador.com.br/gmMV8>. Acessado em: 06 nov. 2020.

BISSERET, N. A ideologia das aptidões naturais. In: DURAND, José Carlos Garcia (org). Educação e hegemonia de classe: as funções ideológicas da escola. Rio de Janeiro: Zahar Editores, 1979.

BOURDIEU, P. Programa para uma sociologia do esporte. In: BOURDIEU, P. Coisas ditas. Trad. Cássia R. da Silveira e Denise Moreno Pegorim. São Paulo: Brasiliense, 1990.

CHAUI, M. A ideologia da competência. Belo Horizonte: Autêntica Editora, 2016.

DANTAS, F. C. Por um urbanismo humanizante: uma utopia meta-pragmática. Revista Brasileira de Sociologia da Emoção, v. 15, n. 44, p. 105-115, 2016. Disponível em: <http://www.cchla.ufpb.br/rbse/ Index.html>. Acesso em: 29 maio. 2018.

DELEUZE, G. \& GUATTARI, F. Mil Platôs: capitalismo e esquizofrenia. Trad. Ana Lúcia de Oliveira. Rio de Janeiro: Editora 34, 2014.

DESCARTES, R. Discurso do método. Trad. J. Guinsburg e Bento Prado Júnior. $4^{a}$ ed. São Paulo: Nova Cultura. (Os Pensadores), 1987. 
DESCARTES, R. Tratado del hombre. Trad. Guillermo Quintás. Madrid, Editora Nacional, 1980. FOUCAULT, M. Vigiar e punir: o nascimento da prisão. Trad. Ligia M. Ponde Vassallo. Petrópolis: Vozes, 1991.

FREUD, S. O Mal-Estar na Civilização (1930 [1929]). In: FREUD, S. Obras Completas. v. XXI. Trad. Jayme Salomão. Rio de Janeiro: Imago, 1990.

GREGORI, L. Mobilidade urbana num período de contradições pela governabilidade. Disponível em: <http://tarifazero.org/2018/04/22/mobilidade-urbana-num-periodo-de-contradicoes-pelagovernabilidade/\#more-6882>. Acesso em: 30 jun. 2018.

GUATTARI, F. \& ROLNIK, S. Micropolítica: cartografias do desejo. $7^{\text {a }}$ Edição. Petrópolis: Vozes, 2005

GUATTARI, F. As três ecologias. Trad. Maria Cristina F. Bittencourt. Campinas: Papirus, 2009.

GUATTARI, F. Restauração da cidade subjetiva. In: BOURDIEU, P. Caosmose. São Paulo: Ed. 34, 2000.

GUATTARI, F. Revolução Molecular: pulsações políticas do desejo. Trad. Suely Belinha Rolnik. São Paulo: Brasiliense, 1981.

IBGE. Instituto Brasileiro de Geografia e Estatística. Disponível em: <https://www.ibge.gov.br/cidades-eestados>. Acesso em 06 nov. 2020.

MAUSS, M. As técnicas corporais. In: MAUSS, M. Sociologia e antropologia. Trad. Mauro W. B. de Almeida. São Paulo: EPU/EDUSP, 1974

MAUSS, M. OUVRES: représentations collectives et diversité des civilisations. Paris: Éditions de Minuit, 1969.

NIETZSCHE, F. Ecce Homo: como alguém se torna o que é. Trad. Paulo Cézar de Souza. São Paulo: Companhia das Letras, 1995.

PLATÃO. A República. Trad. Maria Helena da Rocha Pereira. Lisboa: Fundação Gulbenkian, 1996.

RANCIÈRE, J. A partilha do sensível: estética e política. Trad. Mônica Costa Netto. São Paulo: Editora $34,2009$.

SARTRE, J. P. 0 ser e o nada. Trad. Paulo Perdigão. Petrópolis: Editora Vozes, 1997.

SENNETT, R. Carne e Pedra: o corpo e a cidade na civilização ocidental. Trad. Marcos Arão Reis. Rio de Janeiro: Record, 1997.

SEVCENK, N. Futebol, metrópoles e desatinos. Revista da USP: dossiê futebol. São Paulo, n. 22, p. 30-7, jun./jul./ago, 1994.

WUNENBURGER, J. J. o homem na era da televisão. Trad. Miriam Campolina Diniz Peixoto. São Paulo: Edições Loyola, 2005. 